\title{
NOTAS SOBRE A ESCOLA A LUZ DE LOUIS ALTHUSSER
}

\section{NOTES ON THE LIGHT SCHOOL OF LOUIS ALTHUSSER}

Marli dos Santos de Oliveira ${ }^{1}$

RESUMO: O presente texto tem por objetivo refletir acerca da escola a partir das discussões concernentes aos Aparelhos Ideológicos do Estado de Louis Althusser, por meio de pesquisa bibliográfica e documental, recorrendo a autores que subsidiam as discussões propostas. Historicamente, nota-se a importância dada à escola tanto ao nível individual como também social e, enquanto um Aparelho Ideológico tem a possibilidade de ser o alvo e local das lutas de classe. Percebe-se a necessidade de se (re)pensar a função social da escola, a fim de que, a partir dessas reflexões, compreendam-se, minimamente, os conflitos, as tensões e, sobretudo, as possibilidades, transformadoras dadas a esse espaço social educativo.

Palavras-chave: Louis Althusser. Aparelho Ideológico de Estado. Educação escolar.

ABSTRACT: The present text aims to reflect on the school from discussions concerning the Ideological Apparatus of the State of Louis Althusser, through bibliographical and documentary research, resorting to authors who subsidize the proposed discussions. Historically, we note the importance given to the school both individually and socially, and while an Ideological Apparatus has the possibility of being the target and site of class struggles. It is perceived the need to (re) think the social function of the school, so that, from these reflections, understand, minimally, the conflicts, tensions and, above all, the transformative possibilities given to this space social.

Keywords: Louis Althusser. State ideological apparatus. School education.

\section{Considerações iniciais}

O presente texto tem como objetivo refletir acerca do materialismo histórico-dialético, bem como abordar a escola tendo em vista as reflexões de Louis Althusser, notadamente reconhecido por suas contribuiçõos acerca dos Aparelhos Ideológicos de Estado, e por sua versão estruturalista do marxismo. Destaca-se que os apontamentos feitos ao longo do texto remetem-se a breves reflexões acerca de alguns conceitos do materialismo histórico-dialético, não abarcando, portanto, a imensidão das reflexões e análises realizadas por Marx e os teóricos que o influenciaram, bem como daqueles que deram sequência à suas reflexões. Ademais, dentro dos limites desse texto, espera-se trazer elementos teóricos que permitam refletir acerca da escola tendo em vista a importância social dada historicamente, a esse espaço.

\footnotetext{
${ }^{1}$ Pedagoga pela Universidade Federal de Mato Grosso do Sul. Mestre em Educação pela Universidade Federal da Grande Dourados. Servidora pública municipal. E-mail: marli.oliveiras@ hotmail.com
} 
Nesse sentido, recorrer-se-á as discussões realizadas por Louis Althusser (1919-1990) filósofo francês, visto ter contribuído com sua crítica acerca do economicismo e humanismo que dominavam as leituras de Marx, além de ter ampliado e aprofundado a concepção de Estado marxiana ao criticar a concepção de ideologia como falsa consciência, compreendendo-a como "uma representação da relação imaginária dos indivíduos com as relações de produção e com as relações delas derivadas" (ALTHUSER, 1970, p. 73), emprestando-lhe uma materialidade, tal como se mostrará nesse texto, no conceito de Aparelhos Ideológicos de Estado.

O trabalho organiza-se da seguinte forma: inicialmente, tem-se uma breve exposição acerca do materialismo histórico dialético, apresentando as influências e críticas de Marx feita a alguns teóricos, bem como considerações acerca do Estado burguês. Em seguida, apresenta-se as contribuiç̧ões de Louis Althusser de modo a evidenciar seu conceito de Aparelhos Ideológicos de Estado e suas considerações acerca das diferenças desses para com o Aparelho de Estado tal como concebido por Marx. Posteriormente, discute-se a escola enquanto um Aparelho Ideológico de Estado, tendo em vista sua centralidade no que diz respeito à reprodução das relações de produção e, por fim têm-se as possíveis considerações finais, retomando algumas reflexões levantadas ao longo do texto.

\section{0 materialismo histórico-dialético: algumas considerações}

A perspectiva dialética de base marxista penetrou significativamente no campo educacional brasileiro durante meados da década de 1970 e ao longo dos anos de 1980. Segundo Lénine (1975) durante sua vida Marx continuou e desenvolveu a filosofia clássica alemã, a economia clássica inglesa e o socialismo francês, as três principais correntes ideológicas do século XIX. O autor apresenta que Marx foi materialista, em particular, adepto de Feuerbach. Na obra Fundamentos para a Filosofia do Futuro, Feuerbach desenvolveu o materialismo sob o prisma de humanismo naturista:

O materialismo se apresentava como humanismo reintegrador do homem à sua verdadeira natureza genérica e realizador de suas potencialidades na comunidade do gênero natural. $O$ que implicava o desprendimento das alienações que cindiam o homem consigo mesmo e o separavam dos demais indivíduos do seu gênero (GORENDER, 2001, p. 13).

Marx e Engels não aceitaram com ortodoxia Feuerbach. $\mathrm{Na}$ história universal, os indivíduos foram cada vez mais, submetidos a uma força que lhes é estranha e que se revela em última instância como o mercado mundial. Esse fato, misterioso aos filósofos alemães, só será 
superado, segundo Marx e Engels (2001), pela abolição da propriedade privada e pela revolução comunista - estabelecimento de uma história mundial. É a partir de suas relações reais que os indivíduos serão libertados das limitações locais que se encontram:

A revolução, e não a crítica é a verdadeira força motriz da história, da religião, da filosofia e de qualquer outra teoria. Esta concepção mostra que o fim da história não se acaba resolvendo em "consciência de si", como "espírito do espírito", mas sim que a cada estágio são dados um resultado material, uma soma de forças produtivas, uma relação com a natureza e entre os indivíduos, criados historicamente e transmitidos a cada geração por aquela que a precede, uma massa de forças produtivas, de capitais e de circunstâncias, que, por um lado, são bastante modificadas pela nova geração, mas que, por outro lado, ditam a ela suas próprias condições de existência e lhe imprimem um determinado desenvolvimento, um caráter especifico; por conseguinte as circunstâncias fazem os homens tanto quanto os homens fazem as circunstâncias (MARX; ENGELS, 2001, p. 36).

Os autores salientam que, à época, toda concepção histórica tivera deixado de lado essa base real da história, ou então, a considerado como algo acessório, sem vínculos e, os alemães sempre demonstraram um interesse religioso e local para essas questões. Nesse sentido, a solução prática de eliminação dessas representações sobre os homens, só se realizará, na medida em que ocorra a transformação das circunstâncias existentes e não por deduções teóricas. A esse respeito, Marx e Engels criticam Feuerbach devido a sua dedução, quanto ás relações dos homens, que vê a natureza como algo deslocado do homem - transcendental. Para Feuerbach a história e o materialismo são coisas completamente separadas.

Além disso, Marx repudiou segundo Lénine (1975) o idealismo ligado à religião e o agnosticismo, criticismo de Hume e de Kant. Nos escritos de Hume, encontram-se as bases do empirismo lógico, cujas palavras só tem significado na medida em que se referem a fatos concretos, eliminando-se, portanto, os conceitos da metafísica, uma vez que esta relacionada a realidades exteriores ao sujeito sem qualquer experiência sensível (HUME, 1999). Nesse sentido, Hume faz uma crítica a metafísica uma vez que ela,

[...] não constitui propriamente uma ciência, mas nasce tanto pelos esforços estéreis da vaidade humana que queria penetrar em recintos completamente inacessíveis ao entendimento humano, como pelos artifícios das superstições populares que, incapazes de se defenderem lealmente, constroem estas sarças emaranhadas para cobrir e proteger suas fraquezas. (HUME, 1999, p. 30).

A esse respeito, o autor coloca que a única forma de se libertar dessas questões obscuras é por meio do exame da natureza do entendimento humano mostrando, por meio de uma análise exata de suas faculdades e capacidades, que ela não é adequada a assuntos abstrusos, sendo o 
raciocínio, exato e justo, o único meio de se acabar com a filosofia abstrusa e o jargão metafísico que se afiguram como ciência e sabedoria. Logo, o método filosófico adequado é aquele que permite a contínua reforma das ideais acerca das operações do entendimento humano ${ }^{2}$.

Lénine (1975) aponta e a teoria de Hume exprime bem a concepção burguesa onde a aparência superficial das coisas substitui os processos fundamentais essenciais. Nesse sentido, o autor aponta que o defeito essencial do velho materialismo, incluso o de Feuerbach, era a falta do caráter histórico, dialético, sendo, portanto, metafísico. Não concebia a essência como um conjunto de relações sociais, concretamente determinadas pela história, mas como abstração. Assim, não faziam mais do que interpretar o mundo e, tratava-se, portanto, de transformá-lo.

Nesse sentido, tendo em vista o caráter incompleto e unilateral do velho materialismo, Marx convenceu-se que era preciso "pôr a ciência da sociedade, isto é, o conjunto das ciências chamadas histórias e filosóficas, de acordo com a base materialista e reconstruí-la apoiando-se nessa base" (LÉNINE, 1975, p. 27). Assim, visto o materialismo explicar a consciência pela existência, ele exige, ao ser aplicado à vida social que se explique a consciência social pela existência social:

$\mathrm{Na}$ produção social da própria existência, os homens entram em relações determinadas, necessárias, independentes de sua vontade; essas relações de produção correspondem a um grau determinado de desenvolvimento de suas forças produtivas materiais. A totalidade dessas relações de produção constitui a estrutura econômica da sociedade, a base real sobre a qual se eleva uma superestrutura jurídica e política e à qual correspondem formas sociais determinadas de consciência. O modo de produção da vida material condiciona $\mathrm{o}$ processo de vida social, política e intelectual. Não é a consciência dos homens que determina o seu ser; ao contrário, é o seu ser social que determina sua consciência (MARX, 2008, p. 47).

[...] Não é a consciência que determina a vida, senão a vida é que determina a consciência. Esta não pode ser outra coisa que não o ser consciente e o ser consciente dos homens é o processo de sua vida real. Aqui se ascende da terra ao céu, ao contrário da filosofia alemã, que desce do céu sobre a terra. Aqui partese do homem em carne e osso (GORENDER, 2001, p. 25).

Nota-se, portanto que a concepção materialista da história de Marx eliminou defeitos das teorias históricas anteriores, visto não investigarem as raízes das relações entre os homens além de desconsiderarem a ação das massas da população, sendo que, o materialismo histórico, pela

2 "Todas as ideias, especialmente as abstratas, são naturalmente fracas e obscuras; o espírito tem sobre elas um escasso controle; [...] Pelo contrário, todas as impressões, isto é, todas as sensações, externas ou internas, são fortes e vivas; seus limites são determinados com mais exatidão e não é tão fácil confundi-las e equivocar-nos [...]" (HUME, 1999, p. 38). 
primeira vez, estudou as condições sociais da vida das massas bem como as possibilidades de modificações dessas condições (LÉNINE, 1975).

Considerando o fato de que a natureza procede dialeticamente e não metafisicamente, Marx e Engels utilizaram-se da dialética hegeliana fazendo-a "passar" para sua concepção materialista da história. O mundo escrevia Engels, não deve ser considerado como um complexo de coisas acabadas, mas como um complexo de processos em que as coisas, aparentemente estáveis, passam por uma transformação ininterrupta de mudanças, impondo-se um desenvolvimento progressivo.

Assim, para Marx a dialética é "a ciência das leis gerais do movimento tanto do mundo exterior como do pensamento humano" devendo colocar-se, portanto, também do ponto de vista histórico (LÉNINE, 1975, p. 25):

[...] Neste caminho lógico, movimentar o pensamento significa refletir sobre a realidade partindo do empírico (a realidade dada, o real aparente, o objeto assim como ele se apresenta à primeira vista) e, por meio de abstrações (elaborações do pensamento, reflexões, teoria), chegar ao concreto: compreensão mais elaborada do que há de essencial no objeto, objeto síntese de múltiplas determinações, concreto pensado. Assim, a diferença entre o empírico (real aparente) e o concreto (real pensado) são as abstrações (reflexões) do pensamento que tornam mais completa a realidade observada (PIRES, 1997, p. 97).

Logo, o método materialista histórico-dialético caracteriza-se pelo movimento constante do pensamento humano através da materialidade histórica da vida dos homens, ou seja, através do movimento do pensamento, há que se descobrir as leis que definem a forma organizativa do homem na história da humanidade (PIRES, 1997).

A esse respeito, Marx e Engels (1998, p.10) apontam que a historia da humanidade é a história das lutas de classes. "Homem livre e escravo, patrício e plebeu, senhor e servo, chefe de corporação e assalariado, resumindo, opressor e oprimido estiveram em constante oposição um ao outro [...]". A sociedade burguesa moderna ao brotar-se com o final da sociedade feudal não aboliu os antagonismos das classes e estabeleceu novas condições de opressão, novas formas de lutas, novas classes: burguesia e proletariado ${ }^{3}$.

Marx e Engels (2001) argumentam que todos os conflitos da história têm sua origem na contradição entre as forças produtivas e o modo das trocas, entretanto, esses conflitos não comprometeram sua base fundamental. Lénine (1975) aponta que o marxismo deu origem a

3 Burguesia significa a classe dos capitalistas modernos, que possuem meios da produção social e empregados assalariados. Proletariado, a classe dos trabalhadores assalariados modernos que, por não ter meios de produção próprios, são reduzidos a vender a própria força de trabalho para poder viver (MARX; ENGELS, 1998, p. 9). 
teoria da luta de classes, sendo que somente o estudo do conjunto das aspirações de todos os membros de uma sociedade permite definir, cientificamente, o resultado dessas aspirações. Assim, as aspirações contraditórias nascem da diferença de situação e de condição das classes que compõem a sociedade:

Ocorre que, na sociedade capitalista, o trabalho (atividade vital, essencial) é explorado (comprado por um preço sempre menor do que produz) definindo, assim, um processo de alienação (expropriação da atividade essencial em sua plenitude). Se o trabalho, como atividade essencial e vital traz a possibilidade de realização plena do homem enquanto tal (humanização), a exploração do trabalho determina um processo inverso, de alienação. Sob a exploração do trabalho, os homens tornam-se menos homens, há uma quebra na possibilidade de, pelo trabalho, promover a humanização dos homens (PIRES, 1997, p. 89).

A transformação das forças pessoais em forças materiais causadas pela divisão do trabalho só podem ser abolidas pela abolição da divisão do trabalho, e isso implica, necessariamente, a comunidade. É somente na comunidade que os indivíduos possuem os meios de desenvolverem suas faculdades em todos os sentidos, é somente na comunidade que a liberdade pessoal é possível. Nos sucedâneos a comunidade só existia para aqueles que tinham se desenvolvido nas condições de classe dominante.

Nessa perspectiva, "a diferença entre o individuo pessoal diante do individuo na sua qualidade de membro de uma classe e a contingência das condições de existência para o individuo só aparecem com a classe que é ela própria, um produto da burguesia”. [...] (MARX; ENGELS, 2001, p. 95). Sendo assim, se os proletariados quiserem afirmar-se enquanto pessoas devem abolir suas condições anteriores de existência, ou seja, abolir o trabalho. É necessário colocarem-se em oposição ao Estado, derrubando-o para realizarem sua personalidade.

Assim, nota-se que o materialismo histórico de Marx e Engels não é somente síntese ou soma de elementos anteriores, visto que as ideias não surgiram do vazio cultural. O materialismo histórico-dialético trouxe uma visão profunda e nova sobre as lutas sociais com vistas à transformação radical da sociedade (GORENDER, 2001).

\section{Louis Althusser e a os aparelhos ideológicos de Estado}

A versão estrutural do marxismo, surgida na França em meados de 1960, buscou harmonizar, segundo Carnoy (2005) o pensamento marxista com a natureza aparentemente automática e organizada da sociedade capitalista, onde tanto a classe operária como a burguesia desempenhariam papeis prescritos. A esse respeito, o autor coloca que Althusser queria combater 
o subjetivismo que colocara o homem como sujeito no centro dos sistemas metafísicos, confrontando-o com os atos condicionados e o indivíduo subjugado pelos aparelhos ideológicos.

A visão estruturalista fundamenta-se em dois pontos principais da obra de Althusser. A primeira é a de que a estrutura social não tem em seu núcleo nenhum sujeito criativo. Ele rejeita a noção de homem como sujeito o agente da história argumentando que os indivíduos são "suportes ou portadores" das relações estruturais nas quais se situam. Portanto, são as relações de produção (classes sociais) sujeitas da história e não os atores individuais como agentes livres (CARNOY, 2005).

Para Althusser e para Marx a ideologia é fundamental para a reprodução das relações de produção. O primeiro argumenta que "não são as condições de existências reais, o seu mundo real, que os homens se representam na ideologia, mas é a relação dos homens com estas condições de existência que lhes é representada na ideologia” (ALTHUSSER, 1970, p. 81). Além disso, uma ideologia existe sempre em um aparelho e/ou em suas práticas e isso revela, portanto, que a ideologia tem uma existência material.

A ideologia "enquanto consciência falsa, equivocada, da realidade" pertence ao que Marx denomina de superestrutura. Althusser (1970) expõe que Marx concebe a estrutura de qualquer sociedade como constituídas de níveis articulados por uma determinação específica, ou seja, "a infraestrutura, ou base econômica (unidade das forças produtivas e das relações de produção) e superestrutura, que comporta em si o nível jurídico-político (o direito e o Estado) e a ideologia (as diferentes ideologias religiosas, moral, jurídica, política, etc.)” (ALTHUSSER, 1970, p. 2526).

A esse respeito, fazendo uma alusão a estrutura da sociedade com um edifício, este comporta uma base (infraestrutura) sobre a qual se erguem andares (superestrutura). Percebe-se que os andares superiores não poderão manter-se de pé (no ar) sozinhos, caso não se assentem de fato em sua base. Considerando que a base material é constituída pelas relações de produção, nota-se, portanto que a determinação, em última instância dar-se-ia por questões econômicas.

Nessa direção, a superestrutura não é determinante em última instância, mas determinada pela base, e essa determinação é pensada na tradição marxista sob duas formas: "há uma autonomia relativa da superestrutura em relação à base; há uma ação em retorno da superestrutura sobre a base" (ALTHUSSER, 1970, p. 26). Sobre isso, o autor dispõe que não recusa a alusão clássica da sociedade com um edifício, mas propõe pensar o que ela dá na sua forma descritiva, apontando que é a partir da reprodução que é possível e necessário refletir acerca do que 
caracteriza o essencial da existência e natureza da superestrutura. Sua tese fundamental é, portanto que só se pode refletir acerca dessas questões e respondê-las "do ponto de vista da reprodução" (ALTHUSSER, 1970, p. 27).

Sob esse aspecto, Althusser (1970) propõe-se a analisar o Estado à luz da reprodução. Marx e Engels (2001) indicaram a vinculação do Estado aos interesses de uma classe social determinada, isto é, a classe dominante. "A classe que dispõe dos meios da produção material dispõe também dos meios da produção intelectual, de tal modo que o pensamento daqueles aos quais são negados os meios de produção intelectual está submetido também à classe dominante" (MARX; ENGELS, 2001, p. 48). Logo, se o Estado é o Estado da classe dominante, as ideias dessa classe são dominantes em cada época, parecendo ter validade para toda a sociedade, isto é, para as classes submetidas e dominadas:

[...] o Estado não e outra coisa senão a forma de organização que os burgueses dão a si mesmos por necessidade, para garantir reciprocamente sua propriedade e os seus interesses, tanto externa quanto internamente. [...] conclui-se que todas as instituições comuns passam pela mediação do Estado e recebem uma forma política. (MARX; ENGELS, 2001, p. 75).

Nessa direção, o Estado pode ser resumido a uma "máquina de repressão" que permite as classes dominantes assegurar sua dominação sobre a classe operária, submetendo-os ao processo de extorsão da mais valia ${ }^{4}$ e isso define, portanto, sua função fundamental. Althusser (1970) julga indispensável acrescentar algumas coisas à definição clássica de Estado como aparelho de Estado, e pra isso, resume os clássicos do marxismo que sempre afirmaram:

1) o Estado é o aparelho repressivo de Estado; 2) é preciso distinguir o poder de Estado; aparelho de Estado; 3) o objetivo das lutas de classes visa o poder de Estado e, consequentemente, a utilização feita pelas classes (ou aliança de classes ou de frações de classes), detentoras do poder de Estado, do aparelho de Estado em função dos seus objetivos de classe; e 4) o proletariado deve tomar o poder de Estado para destruir o aparelho de Estado burguês existente, e, numa primeira fase, substituí-lo por um aparelho de Estado completamente diferente, proletário, depois em fases ulteriores, iniciar um processo radical, o da destruição do Estado (fim do poder de Estado) (ALTHUSSER, 1970, p. 38).

Em consonância com o acatado, Althusser (1970) evidencia que para se avançar na teoria do Estado é indispensável, não só a distinção entre poder de Estado e aparelho de Estado, mas

4 Em certo grau do desenvolvimento da produção de mercadorias, o dinheiro transforma-se em capital [...] a fórmula geral do capital é dinheiro-mercadoria-dinheiro, isto é, compra para a venda (com lucro). É a este crescimento do valor do dinheiro posto em principio a circular que Marx chama de mais-valia. [...] Tendo comprado a força de trabalho, o possuidor de dinheiro fica com o direito de a consumir, isto é, de a obrigar a trabalhar durante toda uma jornada, suponhamos doze horas. Mas em seis horas, o operário cria um produto que cobre as despesas do seu sustento, e durante as outras seis horas cria um produto não retribuído pelo capitalista, produto que constitui a maisvalia (LÉNINE, 1975, p. 37-38). 
também outra realidade que se situa manifestamente ao lado do aparelho de Estado, mas não se confunde com ele: os "aparelhos ideológicos de Estado (AIE)", conceito utilizado pelo autor para designar essa realidade.

Sobre isso, o autor argumenta que os aparelhos ideológicos de Estado não se confundem com o aparelho de Estado da teoria marxista que compreende o governo, o exército, a administração, a polícia, os tribunais, as prisões, dentre outras coisas. O autor prefere denominálos de aparelho repressivo de Estado visto funcionarem pela violência. Já em relação aos aparelhos ideológicos de Estado designa-os sob a forma de instituições distintas e especializadas, quais sejam:

O AIE religioso (o sistema das diferentes igrejas), o AIE escolar (o sistema das diferentes escolas públicas e particulares), o AIE familiar, o AIE jurídico, o AIE político (o sistema político de que fazem parte os diferentes partidos), o AIE sindical, o AIE da informação (imprensa, rádio-televisão, etc.), o AIE cultural (Letras, Belas Artes, desportos, etc.). (ALTHUSSER, 1970, p. 44).

A diferença entre o aparelho repressivo do Estado e os aparelhos ideológicos de Estado reside no fato deste ser plural, enquanto que o outro se restringe a um. Além disso, enquanto o aparelho repressivo de Estado pertence ao domínio público, à maioria dos aparelhos ideológicos de Estado, ao contrário, pertencem ao domínio privado. De qualquer forma, o que importa é o seu funcionamento, muito mais do que questões relacionadas ao público e ao privado no estado burguês. Desse modo, registre-se o essencial: o que distingue os aparelhos ideológicos de estado do aparelho repressivo é que, o primeiro funciona pela ideologia, enquanto o segundo pela violência (ALTHUSSER, 1970).

Assim, o aparelho repressivo de Estado funciona secundariamente pela ideologia, prevalecendo à repressão. Inversamente, os aparelhos ideológicos de estado funcionam massivamente pela ideologia e secundariamente pela repressão. Logo, nenhuma classe pode deter o poder de Estado sem exercer, simultaneamente o poder sobre e nos aparelhos ideológicos de Estado. O aparelho repressivo de Estado assegura pela repressão as condições políticas de reprodução das relações de produção, isto é, as relações de exploração.

\section{A escola enquanto Aparelho Ideológico de Estado: alvo e local da luta de classe}

O homem existe no tempo, herda e incorpora saberes e modifica-se, na medida em que não está preso a um hoje, a um tempo reduzido que o esmaga, o homem têm pois, a possibilidade de emergir-se, temporalizar-se (FREIRE, 1996). 
Nesse sentido, segundo Saviani (2003) o homem não se constitui como tal naturalmente, visto que não nasce sabendo pensar, sentir, agir, não nasce, portanto, sabendo ser homem. Logo, para saber sentir, agir e pensar etc. o homem precisa aprender e isso implica, necessariamente, o trabalho educativo.

Sobre isso, o autor considera que esse fenômeno de aprendizagem manifesta-se, inicialmente, pelo próprio ato de viver, progredindo e diferenciando-se, até atingir o caráter institucional revelado com o surgimento da escola. Historicamente, a escola transforma-se então, na forma principal e dominante de educação, no momento em que as relações sociais começaram a prevalecer sobre as naturais, estabelecendo-se, portanto, o mundo da cultura, ou seja, o mundo produzido pelo homem (SAVIANI, 2003). Logo, [...] "não faz o menor sentido discutir abstratamente sobre a educação, pois esta é uma dimensão da vida dos homens que se transforma historicamente, acompanhado e articulando-se às transformações dos modos de produzir a existência dos homens" (LOMBARDI, 2008, p.4).

Dessa forma o autor argumenta que, o avanço das discussões sobre as perspectivas transformadoras da sociedade, pressupõe, necessariamente, as discussões de um projeto de educação também revolucionário, uma vez que a educação é indissociável da sociedade e pode lhe servir de instrumento para a mudança ou para a manutenção das condições de subordinação entre classes da atual sociedade capitalista.

Percebe-se, portanto, a necessidade que o homem tem em se (re)conhecer e compreender a organização social na qual se insere, para que assim, por meio de suas relações sociais, percebaa e torne-se parte dela. Nesse sentido, a educação coloca-se como uma prática que contribui no processo de inserção ativa do homem na sociedade.

Ressalta-se, porém, que não há uma única forma e/ou modelo de educação, afinal como sugere Brandão (2007) devemos falar em educações. Sob essa perspectiva, há muitos pontos importantes que merecem argumentação e discussão, entretanto, toma-se nesse estudo a educação escolar, prática socialmente construída, que por meio de seu trabalho educativo deve possibilitar aos homens a apropriação dos conhecimentos historicamente produzidos, socializando-os.

Saviani (2005) com o auxilio de Althusser e Marx concluiu que é impossível compreender radicalmente a história da sociedade contemporânea e, consequentemente a história da educação contemporânea sem compreender o movimento do capital. Nesse sentido, considera a educação enquanto prática social determinada materialmente e, portanto, o enfoque considerado mais adequado para essa perspectiva de análise, situa-se no âmbito do materialismo histórico. 
Althusser (1970) ao compreender a escola como um Aparelho Ideológico de Estado expressa que como tal, a escola assim como outras instituições é responsável pela reprodução da qualificação da força de trabalho, fato que legitima o espaço que o indivíduo ocupará em sociedade:

Ora, o que se aprende na Escola? Vai-se mais ou menos longe nos estudos, mas de qualquer maneira, aprende-se a ler, a escrever, a contar; portanto algumas técnicas, e ainda muito mais coisas, inclusive elementos (que podem ser rudimentares ou pelo contrário aprofundados) de cultura cientifica ou literária diretamente utilizáveis nos diferentes lugares da produção (uma instrução para os operários, outra para os técnicos, uma terceira para os engenheiros, uma outra para os quadros superiores, etc.). Aprendem-se, portanto, saberes práticos, (savoir faire). (ALTHUSSER, 1970, p. 21).

A escola, além de ensinar as técnicas e os conhecimentos, ensina também regras, bons costumes, seguindo o local que a pessoa ocupará e isso significa, exatamente, regras de respeito pela divisão social-técnica do trabalho, pela ordem estabelecida, pela dominação de classe. Oprimido ou opressor, burguês ou proletário; patrão ou empregado. Nota-se que são inúmeras as denominações, porém todas representam a dominação de uma classe sobre a outra, representam a exploração e desigualdade entre seres humanos.

Nesse sentido, a escola enquanto um aparelho ideológico de estado é instituída e dominada pelo Estado, visto como uma máquina repressiva, que possibilita às classes dominantes assegurar sua dominação sobre a classe proletária. Para o autor, mesmo que seja na escola que se aprenda, se reforce e se perpetue a ideologia dominante, esta não tem origem nela, uma vez que a inculcação das ideias dominantes origina-se na formação das classes sociais, no Estado e em seus aparelhos.

Historicamente, o principal aparelho ideológico de estado dominante era a igreja. A Revolução francesa, segundo Althusser (1970), teve antes de mais o objetivo e o resultado de fazer passar o poder de Estado da aristocracia feudal para a burguesia capitalista-comercial, atacando, consequentemente a igreja e criando novos aparelhos ideológicos de Estado para substituir o então aparelho ideológico dominante.

Nesse contexto, as funções outrora desempenhadas pela igreja passaram para o aparelho ideológico escolar, visto que "[...] nenhum aparelho ideológico de Estado dispõe durante tanto tempo da audiência obrigatória (e ainda por cima gratuita), 5 a 6 dias em 7 que tem a semana, à razão de 8 horas por dia, da totalidade das crianças da formação social capitalista" a não ser a escola (ALTHUSSER, 1970, p. 66). 
Apesar das críticas para com a escola, o autor reconhece que os AIE podem ser não só o alvo, mas também o local da luta de classes o que sugere a possibilidade de mudança nesses espaços que oprimem e legitimam as desigualdades sociais. Sobre isso, ele dispõe que:

Peço desculpas aos professores que, em condições terríveis, tentam voltar contra a ideologia, contra o sistema e contra as práticas em que este os encerra, as armas que podem encontrar na história e no saber que ensinam. Em certa medida são heróis. Mas são raros, e quantos (a maioria) não têm sequer o vislumbre de dúvida quanto ao trabalho que o sistema (que ultrapassa e esmaga) os obriga a fazer, pior, dedicam-se inteiramente e em toda a consciência à realização desse trabalho (os famosos métodos novos!). Têm tão poucas dúvidas, que contribuem até pelo seu devotamento a manter e a alimentar a representação ideológica da escola, que a torna hoje tão natural, indispensável-útil e até benfazeja aos nossos contemporâneos, quanto à igreja era natural, indispensável e generosa para os nossos antepassados de há séculos. (ALTHUSSER, 1970, p.67-68).

Sobre isso, é pertinente destacar que, atualmente, a escola não pode ser encarada como instância única, responsável pela reprodução das desigualdades sociais, haja vista dividir esse espaço com o avanço das tecnologias e da comunicação que influenciam sobremaneira os valores e o modo de agir dos indivíduos. As desigualdades preexistem à escola de modo que, por si só não ela não dá conta de promover as mudanças necessárias. Entretanto, há que se resistir as imposições culturais, inclusive as disciplinares, mas isso implica, necessariamente o saber sistematizado, o desenvolvimento de habilidades. Logo, para se criticar e buscar mudanças sociais junto à escola é necessário, antes de tudo, passar por ela. É paradoxal, mas se faz necessário, fundamental (LIBÂNEO, 2002).

A escola, enquanto aparelho ideológico de estado é claramente um espaço de contradição. É nessas contradições que reside à positividade do aparelho escolar e aí esta um aspecto que merece atenção: a escola deve ser o espaço de desenvolvimento do senso crítico da classe trabalhadora que nela se insere. Como citado outrora no texto, reafirma-se a colocação de Althusser (1970) que a escola deve ser não só o alvo, mas o local da luta de classes.

A esse respeito, registre-se que as ideias apresentadas por Althusser (1970) criticam o existente, explicitam seus mecanismos, mas não apresentam propostas práticas de intervenção, limitando-se a constatar a situação e demonstrar que ela não pode ser mudada, apresentando, portanto, um caráter não dialético, a - histórico. Logo, a prática educativa situa-se no âmbito da reprodução, isto é, no âmbito da inculcação ideológica (SAVIANI, 2003).

A educação escolar é sim determinada pela sociedade, entretanto, essa ação é recíproca, o que significa que a escola ao ser determinada pela sociedade também age sobre seu determinante. 
Portanto, ao interferir na sociedade, a escola pode contribuir para a sua transformação. Assim, a maior necessidade dos indivíduos que compõem o espaço escolar é a de aprender para compreender a vida, compreenderem-se e a toda sociedade, e a escola como um todo deve oferecer-lhes esta experiência.

Sobre as discussões acerca da escola pública, Alves (2006, p.191) apresenta que “[...] diante do comprometimento de sua função propriamente pedagógica, cujos indicadores são o anacronismo de sua organização didática e o aviltamento de seu conteúdo, a escola não tem exercido uma função socialmente útil". A esse respeito, o autor coloca que o espaço escolar, atualmente, serve como um refeitório para os alunos, que se transformou em um importante espaço de convivência social e lazer para as crianças e os jovens, visto que "o espaço escolar tornou-se o único local reservado para eles na sociedade” (ALVES, 2006, p. 207).

Concomitante a isso, Rodrigues (1988) coloca que a escola tem se convertido em aparelho responsável em resolver a questão do desemprego, da fome, da saúde, da segurança, da crise social, etc., e essas funções que lhe são atribuídas tiram sua essência, transformando-a num espaço de múltiplas funções, impedindo-a, portanto, de realizar a sua tarefa central. O problema disso tudo, segundo Alves (2006), é que a escola não está provida das condições necessárias para realizar essas funções que a sociedade a impõe, realizando-as, portanto, precariamente.

\section{Considerações finais}

É difícil finalizar um texto que mais abriu discussões do que encaminhou respostas (LOMBARDI; SAVIANI, 2008). Tentar-se-á, então, fazer as considerações possíveis. Notou-se, por meio desse estudo, que o homem não nasce sabendo ser homem, ele forma-se, produz-se, como tal, sendo esse processo educativo. Logo, a origem da educação coincide, com a própria origem do homem, sendo que, ao longo do tempo, a escola acaba sendo referência e forma dominante de educação em relação às demais.

É fato que para Marx o Estado organiza-se a fim de assegurar, por meio da repressão, os interesses da classe dominante e obviamente, a escola encontra-se sobre a égide do Estado o que em tese, favorece sobremaneira a reprodução das desigualdades sociais. Destaca-se que ele nunca escreveu um texto expressamente dedicado ao tema ensino e educação, o que dificulta argumentar acerca de um sistema pedagógico completo e elaborado tendo em vista suas concepções teóricas. Mas, há escritos de seus precursores que corroboram na discussão acerca da escola e de suas possibilidades reais. 
Nessa direção, Althusser corrobora para se refletir acerca da escola ao considerá-la como um aparelho ideológico de Estado. Percebeu-se que a escola organiza-se a fim de reproduzir as relações de produção, isto é, relações de exploração, ao inculcar nos indivíduos normas, valores, gostos de acordo com a função social que este desempenhará ensinando, portanto, savoir faire.

Entretanto, o próprio autor reconhece que a aparelho ideológico escolar pode ser não só o alvo como também o local da luta de classes, o que evidencia os aspetos positivos da escola, visto que, se ela inculca nos indivíduos os conhecimentos necessários à reprodução das suas condições de produção, ela poderá contribuir também para conscientizar-lhes da exploração a qual estão submetidos, oportunizando-lhes ir do empírico ao concreto pensado. É sem dúvida um desafio, mas há de se buscar essa possibilidade revolucionária nos e dos aparelhos ideológico de estado.

Por fim, constata-se historicamente, a importância da escola tanto ao nível individual como também social. Dado à lógica do capitalismo, o espaço escolar acaba sendo idealizado, por excelência, como o meio possível para inserção, manutenção e ascensão social dos indivíduos. Entretanto, por mais que todos estudem, concluam os mais elevados níveis escolares, não há emprego para todos, haja vista, cada vez mais, todas as contradições do capital.

Logo, é preciso acreditar que, embora a escolaridade não garanta um espaço no mercado de trabalho a todos, ela deve e pode garantir o acesso e a apropriação dos conhecimentos historicamente produzidos, (re)significando-os, utilizando-os como instrumentos de conscientização, de inserção crítica na sociedade, como uma garantia de que o aspecto econômico não seja internalizado nos homens, como superior e predominante ao aspecto social.

Por fim, percebe-se a necessidade de se (re)pensar a função social da escola, a fim de que, a partir dessas reflexões, compreendam-se, minimamente, os conflitos, as tensões e, sobretudo, as possibilidades, transformadoras dadas a esse espaço social educativo.

\section{REFERÊNCIAS}

ALTHUSSER, L. Ideologia e Aparelhos Ideológicos do Estado. [S. 1.: s.n.] 1970.

ALVES, G. L. A produção da escola pública contemporânea. 4.ed. Campinas: Autores Associados, 2006.

BRANDÃO, C. R. O que é educação? São Paulo: Brasiliense, 2007.

CARNOY, M. Estado e Teoria Política. 11. ed. Campinas: Editora Papirus, 2005.

FREIRE, P. Pedagogia da Autonomia: saberes necessários á prática educativa. São Paulo: Paz e Terra, 1996. 
GORENDER, J. Introdução. In: MARX, Karl; ENGELS, Friedrich. A ideologia alemã. Trad: Luis Cláudio de Castro e Costa. São Paulo: Martins Fontes, 2001. (Coleção Clássicos - Filosofia/ Ciências Sociais).

HUME, D. Investigação acerca do entendimento humano. Tradução AnoarAiex. São Paulo: Nova Cultura Ltda, 1999. (Coleção Os pensadores).

LÉNINE, V. I. Karl Marx e o desenvolvimento histórico do Marxismo. Lisboa: Edições Avante, 1975.

LIBÂNEO, J. C. Prefácio. In: VIANA, N.; VIEIRA, R. G. (Orgs.). Educação, Cultura e Sociedade: abordagens críticas da escola. Goiânia: Edições Germinal, 2002.

LOMBARDI, J. C. Educação, Ensino e formação profissional em Marx e Engels. In:

LOMBARDI, J. C.; SAVIANI, D. (Orgs.). Marxismo e educação: debates contemporâneos. 2. ed. Campinas, SP: Autores Associados, 2008.

MARX, K.; ENGELS, F. A ideologia alemã. Trad. Luis Cláudio de Castro e Costa. São Paulo: Martins Fontes, 2001. (Coleção Clássicos - Filosofia/ Ciências Sociais).

MARX, K.; ENGELS, F. O Manifesto Comunista. Trad. Maria Lucia Como. Rio de Janeiro: Paz e Terra, 1998. (Coleção leitura).

PIRES, M. F. de C. O materialismo histórico-dialético e a educação. Revista Interface. Comunicação, Saúde, Educação, v.1, n.1, 1997. Disponível em:

<http://www.scielo.br/pdf/icse/v1n1/06.pdf/>. Acesso em: 30 out. 2015.

RODRIGUES, N. Da mistificação da escola à escola necessária. 2.ed. São Paulo: Cortez, 1988.

SAVIANI, D. Pedagogia Histórico-crítica: primeiras aproximações. 8.ed. Campinas: Autores Associados, 2003.

SAVIANI, D. As transformações do capitalismo, do mundo do trabalho e da educação. In: LOMBARDI, Jose Claudinei; SAVIANI, D.; SANFELICE, J. L. (Orgs.). Capitalismo, trabalho e educação. 3. ed. Campinas: Autores Associados, 2005. (Coleção Educação contemporânea).

Artigo recebido em: 21/06/2017

Artigo aceito em: 26/02/2018 